\title{
The Metadata Education and Research Information Commons (MERIC): A collaborative teaching and research initiative
}

\author{
Sherry L. Vellucci ${ }^{\mathrm{a}}$, Ingrid Hsieh-Yee ${ }^{\mathrm{b}}$ and William E. Moen ${ }^{\mathrm{c}}$ \\ ${ }^{a}$ Rutgers University, School of Communication, Information and Library Science, 4 Huntington Street, \\ CIL 305, New Brunswick, NJ 08901, USA \\ Tel.: +1 732932 7500, ext. 8232; Fax: +1 732932 6916; E-mail: vellucci@scils.rutgers.edu \\ ${ }^{\mathrm{b}}$ Catholic University of America, School of Library and Information Science \\ E-mail: hsiehyee@cua.edu \\ ${ }^{\mathrm{c}}$ University of North Texas, School of Library and Information Sciences, Texas Center for Digital \\ Knowledge, TX, USA \\ E-mail: wemoen@unt.edu \\ Received July 2007 \\ Accepted December 2007
}

The networked environment forced a sea change in Library and Information Science (LIS) education. Most LIS programs offer a mixed-mode of instruction that integrates online learning materials with more traditional classroom pedagogical methods and faculty are now responsible for developing content and digital learning objects. The teaching commons in a networked environment is one way to share, modify and repurpose learning objects while reducing the costs to educational institutions of developing course materials totally inhouse. It also provides a venue for sharing ideas, practices, and expertise in order to provide the best learning experience for students. Because metadata education has been impacted by rapid changes and metadata research is interdisciplinary and diffuse, the Metadata Education and Research Information Commons (MERIC) initiative aims to provide a virtual environment for sharing and collaboration within the extensive metadata community. This paper describes the development of MERIC from its origin as a simple clearinghouse proof-of-concept project to a service-oriented teaching and research commons prototype. The problems of enablers and barriers to participation and collaboration are discussed and the need for specific community building research is cited as critical for the success of MERIC within a broad metadata community.

Keywords: Cataloguing education, metadata education, community building, information commons, teaching and research commons, digital repositories, disciplinary repositories

\section{Introduction}

Digital repositories are one of the fastest growing cyber structures today. They come in a wide variety of configurations, including centralized [9] and distributed [10] storage models, cross-disciplinary [27] and highly specialized subject collections [35], single agency [38] and cross-institutional [9] repositories. Repositories serve different purposes, but they typically focus on collecting, organizing, providing access to, and preserving collected resources outside the more traditional boundaries 
of scholarly communication. Repository functions can be expanded by additional system functionality and user services. One such expanded repository concept is the "teaching and learning commons" [20].

The idea of a teaching and learning commons evolved over the past decade as a result of the many changes affecting higher education. The networked environment forced a sea change in Library and Information Science (LIS) education. Most LIS programs offer a mixed-mode of instruction that integrates online learning materials with more traditional classroom pedagogical methods. In addition to content, LIS faculty are now responsible for developing digital learning objects for use in course management systems, increasing the time spent on teaching preparation. Other factors, such as the rapid and continuous change in LIS fields of study, an increase in non-traditional students, expanding interdisciplinary research, development of distance learning programs, and the focus on interactive learning pedagogies and outcomes assessment, have the cumulative effect of increasing the expense of developing cutting edge, technologically sophisticated courses. The teaching commons in a networked environment seems an obvious solution-a way to share, modify and repurpose learning objects while reducing the costs to educational institutions of developing course materials totally inhouse. It also provides a venue for sharing ideas, practices, and expertise in order to provide the best learning experience for students. The Metadata Education and Research Information Commons (MERIC) initiative will provide this environment for sharing and collaboration within the extensive metadata community [28].

\section{Background}

The original idea for the Metadata Education and Research Information Commons derived from an action plan of the Library of Congress (LC) to prepare future information professionals to organize and provide access to digital resources [4]. In November 2000 the Library of Congress (LC) held an invitational conference to investigate the future of bibliographic control in the digital age. "The primary goals of the Conference were: 1) to develop an overall strategy to address the challenges of improved access to Web resources through library catalogs and applications of metadata; and 2) to identify attainable actions for achieving the overall strategy [4]." To this end, LC developed the Action Plan to follow-up on specific issues identified during the conference [4]. Part of the Action Plan addressed LC's concern that new LIS professionals receive the appropriate cataloguing and metadata education that would prepare them to work in the evolving digital environment and enable them to participate in the development and refinement of metadata standards used both within and outside libraries. Specifically, the goals of Action Item 5.1 were to

"Improve and enhance curricula in library and information science schools by (1) identifying and preparing students with core competencies for library technical services (e.g. interpersonal skills, partnering and analytical skills); (2) devising 
and conducting training to produce flexible and resourceful cataloging professionals with an appropriate mind set and values and advanced problem-solving, operations, management, and information technology skills; and (3) promoting the understanding and use of metadata standards (such as Dublin Core) for describing and managing electronic and digital resources, with the goal of enabling greater participation of new LIS professionals in the development and refinement of metadata standards used both within and outside libraries [4]."

As the Principal Investigator of Item 5.1 of the LC Action Plan, Dr. Ingrid HsiehYee [18] conducted research to determine the current state of LIS curricula in this area, to identify levels of expertise necessary for information professionals to thrive in the metadata environment and to develop a plan that would help educators and practitioners update their knowledge and skills in order to teach and train future and current professionals. Hsieh-Yee's study surveyed existing cataloging and metadata education in North American LIS programs and sought the opinions of expert educators on teaching cataloging and metadata $[18,19]$. Her investigation showed that LIS education in this area continues to lag behind the rapid developments in the broader metadata arena and clearly illustrated the need for more in-depth metadata and cataloging courses in LIS programs. Among her recommendations, Hsieh-Yee proposed the establishment of a "Web Clearinghouse for resources related to teaching cataloging and metadata" [18, p. III].

Educators face several problems that highlight the need for sharing resources. Primary among them is the rapid and continuous change in the area of cataloguing and metadata caused by the dynamic nature of digital objects, the as yet indeterminate changes in the cataloguing code, new conceptual models of the bibliographic universe, evolving catalogue structures and interfaces, and the move away from traditional cataloguing methods to a plethora of organizational systems. This unremitting change and the scatter of the literature make it difficult for educators to keep up with the increasing volume of new information and research in the field and incorporate it into the course content. Pedagogical methods that work well in a face-to-face teaching mode do not always transfer suitably to an online environment, and many educators are not accustomed to a more collaborative process for developing teaching materials. Some instructors share their syllabi and other teaching materials with friends, but a Clearinghouse such as the one recommended by Hsieh-Yee would enable the sharing and reuse of learning objects on a much larger scale.

To ensure the success of the Clearinghouse project LC recruited members of the Association for Library and Information Science Education (ALISE) [2] and the Association for Library Collections and Technical Services (ALCTS) [3], representing both educator and practitioner communities, to undertake the task of planning and implementing the clearinghouse initiative. Thus, MERIC was initially conceived as a basic clearinghouse of cataloguing and metadata teaching materials and related resources. As the project evolved, however, the goals for MERIC expanded beyond the original clearinghouse idea to incorporate the concept of a teaching and research commons. 
Dr. Anita Coleman took the lead in developing a proof-of-concept clearinghouse to demonstrate the potential usefulness of sharing and reusing teaching and learning resources [31]. The Proof-of-Concept Web site contained the original Development Plan, which included a list of possible information organization topics for Clearinghouse resources, types/forms of resources and a selection of sample resources, each with its own metadata description. Coleman gathered a variety of learning object examples appropriate for LIS instruction, continuing education, mentoring, and self-study. These materials included activities (exercises and assignments), articles, bibliographies, crosswalks, FAQs, glossaries, guides and tutorials, interactive resources and services, presentations, online books, software, standards, syllabi, tests and quizzes, and units of instruction. The proof-of-concept model provided links to a resource, which resided elsewhere on the Web. Coleman brought a knowledge organization perspective to cataloguing and metadata, and included such topics as indexing, ontologies, and information architecture. She also expanded the affiliate communities to include digital libraries, digital repositories, information architects, standards organizations, specialist groups and information scientists. In her final Report on the project, Coleman identified specific issues to be addressed, including content ownership, ethical and intellectual property rights, collection development and use policies, and of course, metadata standards.

\section{A new vision: From clearinghouse to teaching and research commons}

Encouraged by the possibilities demonstrated by the proof-of-concept Clearinghouse, the ALCTS/ALISE Task Force on Preparing Cataloging and Metadata Educators and Trainers recommended that an Advisory Board be appointed to develop an operational prototype. The Board would serve under the auspices of the ALISE Technical Services SIG with liaison to ALCTS's Cataloging and Classification Section Committee on Education, Training, and Recruitment for Cataloging (CETRC) and the Library of Congress, which offered to host the project. The Board initially named the prototype the Metadata Education and Research Information Center (MERIC) and began working with LC on specifications to design the infrastructure, navigation, and search and display components of the system; to develop administrative guidelines for collection development, submission and use of materials; and to develop a review process for evaluating the quality of the learning objects' content and the overall success of the MERIC initiative.

As this initial phase of prototype development progressed, two things occurred that altered the course of the initiative. First, due to fiscal constraints, the Library of Congress was no longer able to host the MERIC Initiative and the Board sought a new collaborative partner willing to help develop and host the prototype. Fortunately, Dr. William E. Moen offered to have the graduate students in his Spring 2006 course, Metadata and Networked Information Organization and Retrieval, collaborate with the Advisory Board on developing and implementing the new MERIC prototype; it 
would reside at the University of North Texas (UNT) during this phase of development. Secondly, the Advisory Board began to investigate the concept of a "teaching commons," as recommended by the Carnegie Foundation for the Advancement of Teaching, where "communities of educators committed to pedagogical inquiry and innovation come together to exchange ideas about teaching and learning and use them to meet the challenges of educating students ..." [20]. The networked environment provides an ideal venue for collaborative work; the open-source technology for creating such a virtual space is readily available; and the LIS field, especially the cataloging community, has a long history of cooperation and resource sharing. Instructors often reuse their own materials and incorporate materials from various other sources $[6,8,23]$. Studies have identified the benefits of sharing learning objects in higher education [23]. The cost for creating online courses and the necessary learning objects, however, is high and the nature of topics in the field of metadata are increasingly complex and challenging. Development of new instructional materials can pose financial burdens on institutions of higher education [23]. This burden can be lessened by sharing learning objects for course development. The possibility of providing a virtual environment for collaborative teaching, learning and research captured the Board's interest. The vision for MERIC was expanded from a clearinghouse to a teaching and research commons and the initiative was renamed MERIC: the Metadata Education and Research Information Commons. By drawing on the collective experience, effort, and wisdom of the metadata community and by taking advantage of advanced network technology, MERIC will enable LIS educators to keep up-to-date in their field, provide better metadata education to practitioners and students, and advance metadata research in a more effective and less costly fashion.

\subsection{Prototype development}

The evolving vision for MERIC is as a web-based application comprised of 1) a metadata-driven digital repository of learning objects and research resources; 2) system features to encourage and facilitate research; 3) system features to support collaboration among metadata educators, trainers, practitioners, and researchers; and 4) principles, policies, a governance structure, and related social agreements to support a community of practice. With Moen directing the project, the UNT students designed, developed, and implemented a repository-based application.

The MERIC application is designed as a service-oriented architecture. Web services are defined as "self-contained, modular applications that can be described, published, located, and invoked over a network, generally, the World Wide Web" [21]. The service-oriented architecture plays three roles, including service provider, service requester and service broker. Any particular network service component can play any or all of these roles [21]. The MERIC architecture is intended to present a range of services to support the teaching and research commons envisioned by the MERIC Board. Figure 2 provides a diagram of the Service-Oriented Architecture structure. 
The two primary open source components of this architecture are the MERIC Website and the MERIC Repository, each of which is a separate application. The MERIC Website is the gateway to all MERIC services, both publicly available and/or authenticated user services [28]. The Drupal Content Management System, which is used as the MERIC Website platform, ensures ease of maintenance and dynamic generation of web pages and other aspects of the website [12]. The MERIC Repository supports submission, metadata creation, storage, and access functions. The project team selected DSpace for the repository platform, as it met most of the functional and technical requirements identified by the MERIC Advisory Board [13]. Some repository services, such as learning object and document submission, are provided by the native user interface of the application, while other features use web services to support user interaction with the repository from the website.

A number of services may be supported through the combined functionalities of the website, the repository, and other applications. Possible user services to be supported include user registration, online submission of resources, metadata generation templates, searching, browsing and access, online peer-review and feedback, discussion, news and alert services. During the six-month design and implementation period, the project team was extremely productive. The students installed and customized Drupal and DSpace to provide a common look and feel for MERIC; they created a MERIC Application Profile for the supporting metadata scheme [29]; they developed an extensive set of rules to guide the creation of metadata records for all MERIC resources [30]; and they conducted an initial user testing of the application. Various draft and final project documents are available on the MERIC site [28].

A standard search protocol, Search and Retrieve URL/Web Service (in the form of SRU), was used to power the Access Service component of the application [36]. SRU provides the repository with a standard XML-based search interface and enables easier customization of user interfaces for both searching and presentation of results. The protocol demonstrates the power of separating interfaces from the underlying applications, and provides standards-based access to MERIC for federated searching. Additional access was ensured by the use of OAI-PMH compliant metadata [33].

The prototype currently provides three ways to access the materials in MERIC: basic search, advanced search and browse. Figure 3 shows the browse screen with a list of Resource Types.

Additional content for MERIC might include information on pedagogy and instructional design, information on research methodologies, information on and use of new technologies such as blogs, wikis, PDAs, RSS feeds, and PodCasting, and a calendar of events listing upcoming conferences and educational opportunities.

Since MERIC is a metadata-driven application, metadata records must be created and submitted with each resource. The metadata scheme developed in the Application Profile employs the Dublin Core Metadata Element Set [15] as the primary scheme, which is then refined and augmented by data elements from the GEM [17], MODS [32] and DSpace [14] metadata element sets. The metadata guidelines prescribe the use of required and recommended descriptive and administrative data 
elements. The resource submitter may request online assistance with the metadata creation if necessary. The Board developed a preliminary subject taxonomy, however, contributors can assign additional terms as necessary. Figures 4 and 5 provide examples of brief and full metadata records for a MERIC resource, respectively.

\section{Future directions: Conducting research as a basis for design}

Community building is the key driver in creating a collaborative teaching and research commons. In their research on institutional repositories, Foster and Gibbons [16] found that it was essential for the repository to be supported by the community of practice to be effective. In order for MERIC to accomplish its goals, the following groups must support the initiative in some way, either as active contributors and users, or as supporters of the concept of a teaching and research commons: 1) LIS educators and researchers in the broad spectrum of information organization, including metadata, cataloging, indexing, information architecture and the Semantic Web; 2) trainers who conduct workshops for continuing education, or specific projects within an institution; 3) metadata practitioners, researchers, or developers within the LIS field and in allied disciplines; 4) publishers, professional associations, and information agencies that produce valuable resources for the metadata community; and 5) LIS program administrators, deans and directors of organizations whose faculty or staff are potential members of the MERIC community. Although not all of these stakeholders would be active participants in the MERIC community of practice, it is important for each of these groups to support the MERIC initiative. It is not a given, however, that each group will see the benefits of doing so. Research is needed to identify the human and social dimensions of a virtual MERIC community before proceeding to build a production level system. Previous research confirms that there are incentives for and barriers to sharing and reusing learning objects in institutions of higher education. According to Lavitt [22] and Uijtdehaage et al. [37], incentives include factors such as reward and recognition. The question remains "what types of rewards and recognition would encourage potential members of the MERIC community to contribute resources to MERIC?" Previous research also showed that factors such as control of academic content, quality of the objects, ownership, and copyright can be impediments for knowledge sharing [1,5-7,37]. These factors must be examined to determine whether they hold for MERIC stakeholders and whether any additional factors exist that will act as barriers to participation. We must then find viable solutions to these problems that respond effectively to specific MERIC community concerns. Thus, the culture, values, and expectations of potential community members and supporters must be understood and used as the basis to design the structure, policies and processes for such an information commons.

It is critical that the MERIC community embrace a model of collaboration as well as sharing. Collaboration can take many forms, including the development of learning objects or entire courses, planning workshops and conferences, and 
collaborative research projects. The best collaborative metadata research involves a cross-fertilization of ideas and methodologies among educators and practitioners, yet finding common ground to develop this type of collaboration is not easy. Hopefully, MERIC will provide a useful and innovative space to support and encourage new collaborative research in areas of interest to the MERIC community. A primary concern of the fields of computer supported collaborative work and collaborative learning, however, is how groups adopt collaborative technology to support work in a distributed environment. Studies have found that adoption is greatly affected by the cultures, values, and practices of the social worlds of potential participants [24,25,34]. Mattessich et al. [26] identified six categories that can make or break collaborative efforts: environment; membership; structure and process; communication; purpose; and resources. These categories must be understood as they apply to the potential MERIC community, and considered in the final design of the production level system.

Findings from all of these studies suggest that the belief that "build it and they will come" is not a valid assumption regarding virtual repositories or information commons. Research on community building that is specific to the metadata education and research sector is needed in order to ensure a firm foundation for MERIC. The primary focus of such research will be to investigate the critical factors affecting participation in the MERIC community of practice and to develop positive responses in terms of governance structure, principles, policies and system features that would encourage sustained participation in the MERIC community.

\section{Conclusions}

The MERIC initiative, when completed, will provide a new collaborative model that enables educators and trainers to design, use, and share learning objects for metadata education; will promote integration of metadata into LIS curricula; will help LIS educators and trainers to keep up with metadata research conducted in various disciplines; and will facilitate their interaction with researchers inside the LIS field and in the wider metadata community. The current MERIC prototype implementation is now being tested by potential MERIC users. Hopefully, the proposed research to identify the factors affecting stakeholders' participation and collaboration will lay the socio-technical foundation for MERIC and the solid empirical data will enable us to build a user-centered teaching and research commons and a stronger community of practice for MERIC that is based on reality rather than assumption.

\section{Acknowledgements}

The original MERIC Advisory Board members were Ingrid Hsieh-Yee and Sherry L. Vellucci, co-chairs, Anita S. Coleman (ALISE TS SIG Convener), C. Olivia Frost, Patricia Lawton, Shawne D. Miksa, and Steven J. Miller (CETRC representative). 
Current Advisory Board members include Ingrid Hsieh-Yee and Sherry L. Vellucci, co-chairs, C. Olivia Frost, Barbara Marson (ALISE TS SIG Convener), Steven J. Miller (CETRC representative), William E. Moen, and Katherine Wisser.

\section{References}

[1] S. Acker, D. Pearl and S. Rissing, Is The Academy Ready for Learning Objects?, in: Learning Objects: Contexts and Connections, C.M. Gynn and S.R. Acker, eds, Ohio: Ohio State University, 2003, pp. 83-89.

[2] Association for Library and Information Science Education (ALISE). Retrieved June 8, 2007 from http://www.alise.org/.

[3] Association for Library Collections and Technical Services (ALCTS). Retrieved June 8, 2007 from http://www.ala.org/ALCTSTemplate.cfm?Section=alcts.

[4] Bibliographic Control of Web Resources: A Library of Congress Action Plan (Introduction). Retrieved June 8, 2007 from http://www.loc.gov/catdir/bibcontrol/actionplan.html.

[5] T. Brabazon, Digital Hemlock: Internet Education and the Poisoning of Teaching. Sydney: University of New South Wales Press, 2002.

[6] L. Campbell, Engaging with the Learning Object Economy, in: Reusing Online Resources: A Sustainable Approach to E-Learning, A. Littlejohn, ed., London: Kogan Page, 2003, pp. 35-45.

[7] K. Chitwood, C. May, D. Bunnow and T. Langan, Battle Stories from the Field: Wisconsin Online Resource Center Learning Objects Project, in: The Instructional Use of Learning $O b$ jects: Online, Version, D.A. Wiley, ed., 2000. Retrieved June 8, 2007 from http://reusability.org/ read/chapters/chitwood.doc.

[8] B. Collis and A. Strijker, Technology and Human Issues in Reusing Learning Objects, Journal of Interactive Media in Education 4 (2004), 1-32. Retrieved June 8, 2007 from http://www-jime. open.ac.uk/2004/4/collis-2004-4.pdf.

[9] Cornell University Library. Cornell Digital Repository. Retrieved June 8, 2007 from http://dspace. library.cornell.edu/index.jsp.

[10] DLESE. Digital Library for Earth System Education. Retrieved June 8, 2007 from http://www. dlese.org/library/index.jsp.

[11] DLIST. Digital Library of Information Science and Technology. Retrieved June 8, 2007 from http://dlist.sir.arizona.edu/.

[12] Drupal. Retrieved June 8, 2007 from http://drupal.org/.

[13] DSpace. Retrieved June 8, 2007 from http://www.dspace.org/.

[14] DSpace Metadata. Retrieved June 8, 2007 from http://www.dspace.org/technology/metadata.html.

[15] Dublin Core Metadata Initiative. Dublin Core Metadata Element Set, Version 1.1. Retrieved June 8, 2007 from http://dublincore.org/documents/dces/.

[16] N.F. Foster and S. Gibbons, Understanding Faculty to Improve Content Recruitment for Institutional Repositories, D-Lib Magazine 11(1) (2005). Retrieved June 8, 2007 from http://www.dlib.org/ dlib/january05/foster/01foster.html.

[17] Gateway to $21^{\text {st }}$ Century Skills. GEM Documentation. Retrieved June 8, 2007 from http://www. thegateway.org/about/documentation/.

[18] I. Hsieh-Yee, Cataloging and Metadata Education: A Proposal for Preparing Cataloging Professionals of the 21st Century, A report submitted to the ALCTS-Education Task Force in response to Action Item 5.1 of the 'Bibliographic control of Web Resources: A Library of Congress Action Plan,' Approved by the Association for Library Collections and Technical Services, 2002-2003. Retrieved June 8, 2007 from http://lcweb.loc.gov/catdir/bibcontrol/CatalogingandMetadataEducation.pdf.

[19] I. Hsieh-Yee, Cataloging and Metadata Education in North American LIS Programs, Library Resources \& Technical Services 48(1) (2004), 59-68.

[20] M.T. Huber and P. Hitchings, The Advancement of Learning: Building the Teaching Commons: a Carnegie Foundation Report on the Scholarship of Teaching and Learning in Higher Education, Stanford, California: Jossey-Bass, 2005. 
[21] IBM. DevelopersWorks. Web Services Architecture Overview: The Next Stage of Evolution for E-Business. Retrieved June 8, 2007 from http://www.ibm.com/developerworks/library/w-ovr/.

[22] N. Lavitt, Institutional Use of Learning Objects Three Years On: Lessons Learned and Future Directions, in: Learning Objects 2003 Symposium: Lessons Learned, Questions Asked, E. Duval, W. Hodgins, D. Rehak and R. Robson, eds, 2003, pp. 39-43. Retrieved June 8, 2007 from http://www.aace.org/conf/edmedia/LO2003Symposium.pdf.

[23] A. Littlejohn, An Incremental Approach to Staff Development in the Reuse of Learning Resources, in: Reusing Online Resources: A Sustainable Approach to E-Learning, A. Littlejohn, ed., Sterling, VA: Kogan Page, 2003, pp. 221-233.

[24] G. Mark and S. Poltrock, Diffusion of a collaborative technology cross distance, in: Proceedings of the 2001 International ACM SIGGROUP Conference on Supporting Group Work, New York: ACM Press, 2001, 232-241.

[25] G. Mark and S. Poltrock, Shaping Technology Across Social Worlds: Groupware Adoption in a Distributed Organization, in: Proceedings of the 2003 International ACM SIGGROUP Conference on Supporting Group Work, New York: ACM Press, 2003, 284-293.

[26] P.W. Mattessich, M. Murray-Close and B.R. Monsey, Collaboration: What Makes It Work, 2nd ed., Saint Paul, Minn.: Amherst H. Wilder Foundation, 2001.

[27] MERLOT: Multimedia Education Resource for Learning and Online Teaching. Retrieved June 8, 2007 from http://www.merlot.org/merlot/index.htm.

[28] MERIC: Metadata Education and Research Information Commons. Retrieved June 8, 2007 from http://meric.lis.unt.edu/.

[29] MERIC Application Profile. Draft 5. (July 17, 2006). Prepared by the MERIC Project Team under the supervision of Dr. William E. Moen. Retrieved June 8, 2007 from http://meric.lis.unt.edu/?q=node/8.

[30] MERIC Metadata Creation Guide. Draft 5. (July 17, 2006). Prepared by the MERIC Project Team under the supervision of Dr. William E. Moen. Retrieved June 8, 2007 from http://meric. lis.unt.edu/?q=node/8.

[31] Metadata and Cataloging Education Web Clearinghouse Prototype. Retrieved June 8, 2007 from http://www.sir.arizona.edu/faculty/coleman/lc/final/.

[32] Metadata Object Description Schema (MODS). Retrieved June 8, 2007 from http://www.loc.gov/ standards/mods/.

[33] Open Archives Initiative-Protocol for Metadata Harvesting (OAI-PMH). Retrieved June 8, 2007 from http://www.openarchives.org/pmh/.

[34] W.J. Orlikowski, CASE Tools as Organizational Change: Investigating Incremental and Radical Changes in Systems Development, MIS Quarterly 17(3) (September 1993), 309-340.

[35] SHODOR Education Foundation: A National Resource for Computational Science Education. Retrieved June 8, 2007 from http://www.shodor.org/.

[36] SRU: Search/Retrieve Via URL. Retrieved June 8, 2007 from http://www.loc.gov/standards/ sru/; SRW: Search/Retrieve Web Service. Retrieved June 8, 2007 from http://www.loc.gov/standards/ sru/srw/index.html.

[37] S.H.J. Uijtdehaage, J. Contini, C.S. Candler and S.E. Dennis, Sharing Digital Teaching Resources: Breaking Down Barriers by Addressing the Concerns of Faculty Members, Academic Medicine 78(3) (2003), 286-294.

[38] University of Rochester. UR Research. Retrieved June 8, 2007 from https://dspace.lib.rochester. edu/index.jsp. 
Copyright of Education for Information is the property of IOS Press and its content may not be copied or emailed to multiple sites or posted to a listserv without the copyright holder's express written permission. However, users may print, download, or email articles for individual use. 